Cerebrovasc Dis 2010;29:403-407

DOI: $10.1159 / 000288054$

\section{Different Patterns of Lateralization of Cognitive Functions in a Left-Handed Patient with Unilateral Right Middle Cerebral Artery Stroke}

\author{
Valérie Beaud Goetschmann, Alexandre Croquelois
}

Neuropsychology and Neurorehabilitation Service, Centre Hospitalier Universitaire Vaudois and University of Lausanne, Lausanne, Switzerland

\section{Introduction}

Functional lateralization is one of the main characteristics of the human brain. Classically, the left hemisphere is dominant for language and limb praxis, and the right hemisphere for visuospatial abilities, but exceptions exist, particularly in left-handed and ambidextrous individuals. Rasmussen and Milner [1] showed that $96 \%$ of right-handers and $70 \%$ of non-right-handers had speech disturbances after Amytal injection into the left hemisphere. Among right-handers, none had a bilateral, and $4 \%$ showed a right-sided speech representation. In non-right-handers, the corresponding proportions were 15 and 15\%, respectively. Recently, a study using functional transcranial Doppler ultrasonography during 2 tasks of visuospatial attention and word generation has revealed that $97 \%$ of right-handers showed left-hemispheric language dominance and 95\% right-hemispheric attentional dominance, while the results for left-handers were 74 and $81 \%$, respectively [2]. It was also demonstrated that the lateralization of language and spatial attention into different hemispheres is not an invariable characteristic of human brain organization. Rather, an association of both language and visuospatial attention with the right or the left hemisphere [2,3], respectively, might also exist. Furthermore, the same hemisphere can be dominant for both language and spatial attention not only in individuals with atypical patterns of language lateralization, but also in subjects showing the standard left-hemispheric dominance for language. Thus, in healthy subjects the cerebral cortex would be able to organize the representation of cognitive functions differently than the 'standard' pattern at no apparent behavioral cost $[2,3]$. Another study of healthy subjects showed a correlation between language lateralization and handedness [4]. Subjects in whom the side of language dominance corresponds to the side of handedness had a stronger lateralization than those in whom these items were dissociated. A more bilateral lateralization, i.e. bilateral processing of functions, was observed when the dominance of handedness and language did not fall into the same hemisphere. This might help explain why patients with atypical lateralization seemed to have slightly less severe aphasia than patients with a typical brain organization [5]. In addition, the more right-handed the subjects were, the lower was the relative incidence of right-hemispheric language dominance, and vice versa [4]. Thus, there was a linear relationship between the degree of handedness and the side of language dominance. Finally, a stronger bilateral activation in left-handers has been demonstrated during a sentence-processing task [6].

Myriad varieties of atypical brain organization have been described in brain-injured patients including cases of partially reversed cerebral lateralization in right- and left-handed patients [7-10], cases of a completely reversed laterality of cerebral dominance in right- and left-handed patients $[11,12]$ and, finally, a case of complete lateralization of all cognitive functions in the same hemisphere in a left-handed patient [13].

We here report the case of a left-handed patient who presented potentially 3 different patterns of lateralization following a unilateral right-hemispheric stroke.

Case Report

A 54-year-old man, fully left-handed (decile 1 of left-handers in the Edinburgh Inventory [14]), with known hypertension and paroxysmal atrial fibrillation, on $\beta$-blocking agent and without known cognitive deficits, was admitted to the emergency room with left hemiparesis and dysarthria. On admission, the neurological examination revealed a moderate left hemiparesis, left hemianopia and left visual hemineglect. A perfusion CT revealed a right middle cerebral artery (MCA; M2 segment) occlusion and parietotemporal hypoperfusion characterized by a decreased cerebral blood flow, an increase in mean transit time but a preserved or even increased cerebral blood volume (penumbra) [15]. He received no acute-phase treatment as his hemiparesis spontaneously improved. A first short neuropsychological screening took place 2 days after stroke onset (table 1 ). The patient was oriented and cooperative. Language testing revealed few phonemic paraphasias in spontaneous speech and long pauses during conversation. Writing was characterized by downstroke perseverations. A significant latency in simple oral calculations and procedural errors in a basic written calculation were noted, as well as egocentric right-left confusion and signs of left hemispatial neglect. The patient presented difficulties in linking 3 gestures in order, while each of the 3 gestures was properly done. The deficit relates to the transition to a dynamic series of 3 movements [16].

At 15 days after stroke, the patient was admitted to the rehabilitation unit and had a second, more extensive, neuropsychological assessment (table 1) before the cognitive rehabilitation

\section{KARGER}

Fax +41613061234 E-Mail karger@karger.ch www.karger.com
(C) 2010 S. Karger AG, Basel

$1015-9770 / 10 / 0294-0403 \$ 26.00 / 0$ 
Table 1. Results of neurological screenings

First short neuropsychological Second assessment

Expected scores

screening

(depending on age

and level of education)

\section{Oral language}

Spontaneous speech

Picture naming (Boston Naming)

Verbal fluency (semantic)

Verbal fluency (phonetic)

Word and sentence repetition

Word spelling

Understanding instructions during the examination

Listening comprehension (Token Test)

Written language

Writing

Keyboard writing

Reading

Reading comprehension (E.CO.S.SE test)

Calculation

Oral

Written
Few phonemic paraphasias

(1 word out of 10)*

Within limits
Few phonemic paraphasias

(1 word out of 15$)^{*}$

$34 / 34 \quad>28$

22 words in $60 \mathrm{~s} \quad>15$

9 words in $60 \mathrm{~s}^{*} \quad>10$

$10 / 10$ words; $5 / 5$ sentences

$20 / 20$

Executive task instructions difficult to integrate (see Executive functions)* $34 / 36$
Downstroke perseverations ( 2 out of 4 words)*

Perfect, except slowing down during transition to next line*
Slow, laborious and hesitant (>20 min for writing 54 words)* 20/20

Rare left omissions and slowing down during transition to next line* $80 / 92^{*}$

$>80.7$

\section{Praxis}

Ideomotor praxis

Pantomiming tool use

Imitation of meaningless gestures

Ideational praxis

Demonstrating the use of objects

Constructive praxis

Flower (copy)

Cube (copy)

Gnosia

Left/right orientation

On self

On someone else

Digital gnosia

Recognition of fingers test

In-between test

Two-point finger test

Visual gnosia

Identifying overlapping figures

Recognizing celebrities

Benton Face Recognition Test

Visual Object and Space Perception Battery

Screening test

Incomplete letters

Silhouettes

Object decision

Progressive silhouettes

Dot counting

Position discrimination

Number location

Cube analysis
Important latency in simple operations*

Procedural errors in 1 addition*
Partial loss of multiplication tables*

Complete procedure loss in subtractions and multiplications*

$\begin{array}{ll}4 / 4 & 4 / 4 \\ 4 / 4 & 4 / 4\end{array}$

Omission of 1 item on left side

Slowness in programming $(>2 \mathrm{~min})^{*}$
$0 / 6^{*}$

$2 / 6^{*}$

$1 / 6^{*}$

$20 / 20$

$13 / 20^{*}$

$14 / 20^{*}$

$25 / 25$

$5 / 5$

$21 / 27$

$20 / 20$

$16 / 20$

$25 / 30$

$16 / 20$

$10 / 20$

$9 / 10$

$20 / 20$

$8 / 10$

$6 / 10$
$>18$

$>14$

$>15$

$>14$

$>13$

$<16$

$>7$

$>17$

$>6$

$>5$ 
Table 1 (continued)

\begin{tabular}{|c|c|c|c|}
\hline & $\begin{array}{l}\text { First short neuropsychological } \\
\text { screening }\end{array}$ & Second assessment & $\begin{array}{l}\text { Expected scores } \\
\text { (depending on age } \\
\text { and level of education) }\end{array}$ \\
\hline \multicolumn{4}{|l|}{ Spatial attention } \\
\hline Flower (copy) & Omission of 1 item on left side* & & \\
\hline Reading & $\begin{array}{l}\text { Slowdown during transition to } \\
\text { next line }(>5 \mathrm{~s})^{*}\end{array}$ & $\begin{array}{l}\text { Rare left omissions and slowdown during } \\
\text { transition to next line }(>5 \mathrm{~s})^{*}\end{array}$ & \\
\hline Line bisection & & Right directional bias $(+13.5 \mathrm{~mm})^{*}$ & $<6.5 \mathrm{~mm}$ \\
\hline Writing & & Left margin $(5.5 \mathrm{~cm})$ & Left margin $<8.6 \mathrm{~cm}$ \\
\hline Bell cancellation test & & $34 / 35$ (1 left omission) & $<7$ omissions \\
\hline \multicolumn{4}{|l|}{ Diotic listening test } \\
\hline Left ear & & $14 / 30$ & $>8.6$ \\
\hline Right ear & & $26 / 30$ & $>10.4$ \\
\hline Asymmetry & & 30 (left ear disadvantaged)* & $<22.9$ \\
\hline \multicolumn{4}{|l|}{ Memory } \\
\hline \multicolumn{4}{|l|}{ Short-term memory } \\
\hline Digit span & 6 & 6 & $>4$ \\
\hline Corsi span & & 5 & $>3$ \\
\hline \multicolumn{4}{|l|}{ Working memory } \\
\hline Words spelled in reverse & & $8 / 8$ & \\
\hline Update test & & $\begin{array}{l}\text { Average response time: } 641 \mathrm{~ms} \text { (PC 31); } \\
\text { fluctuations in response time: } 112 \mathrm{~ms}\end{array}$ & \\
\hline \multicolumn{4}{|l|}{ Anterograde memory } \\
\hline Recall of the review & Correct & & \\
\hline Recognition of landscapes & & $10 / 40^{*}$ & $>19$ \\
\hline Recognition of words & & $37 / 40$ & $>27$ \\
\hline \multicolumn{4}{|l|}{ Executive function } \\
\hline Verbal fluency (phonetic) & & 9 words in $60 \mathrm{~s}^{*}$ & $>10$ \\
\hline Figural fluency & & 13 drawings in $3 \mathrm{~min}$ & $>20.5$ \\
\hline Gestural sequences (3) & 2 sequences in $30 \mathrm{~s}^{*}$ & 8 sequences in $30 \mathrm{~s}$ & $>3$ \\
\hline Bimanual coordination & Left-hand under-use* & 9 sequences in $30 \mathrm{~s}$ & $>7$ \\
\hline Frises de Luria & & $99 \mathrm{~s}^{*}$ & $<86 \mathrm{~s}$ \\
\hline Trail Making Test (A and B) & & $\begin{array}{l}\text { Not possible because of difficulties in } \\
\text { understanding instructions* }\end{array}$ & \\
\hline Six Elements test & & $\begin{array}{l}\text { Not possible because of difficulties in } \\
\text { understanding instructions* }\end{array}$ & \\
\hline Wisconsin Card Sorting Test & & $\begin{array}{l}\text { Not possible because of difficulties in } \\
\text { understanding instructions* }\end{array}$ & \\
\hline
\end{tabular}

Attention

Alerting (attention evaluation test)

Phasic

Med: PC 5 (331 ms); SD: PC $<1(169 \mathrm{~ms})^{*}$

Tonic Med: PC 1 (430 ms); SD: PC $<1(175 \mathrm{~ms})^{*}$

* Abnormal. E.CO.S.SE = Epreuve de compréhension syntaxico-sémantique - syntax-semantic comprehension task; PC = percentile; Med = median.

took place. The patient spontaneously reported difficulties in calculation and reading the time. He also noted a few phonemic paraphasias and some writing problems. He tended to hit the furniture on the left while walking and was not able to integrate multiple simultaneous instructions. When asked, he reported concentration and memory problems, psychomotor slowing with a significant latency and fatigability. He was quickly overwhelmed with new activities and irritable. This reflected a relatively preserved awareness of cognitive deficits.
During the examination, we noted frustration, perplexity, hesitation, indecision, intellectual slowing and anxiety, which could lead to an emotional reaction to failure, with blocking and even conflict with the therapist. The following cognitive disorders were noted: language - phonemic paraphasias, difficulties to execute some oral instructions (particularly those concerning the executive tasks), slow, laborious and hesitant writing with distorted and imprecise letter formation, downstroke perseverations, rotation and mirror errors in physically similar letters and, 


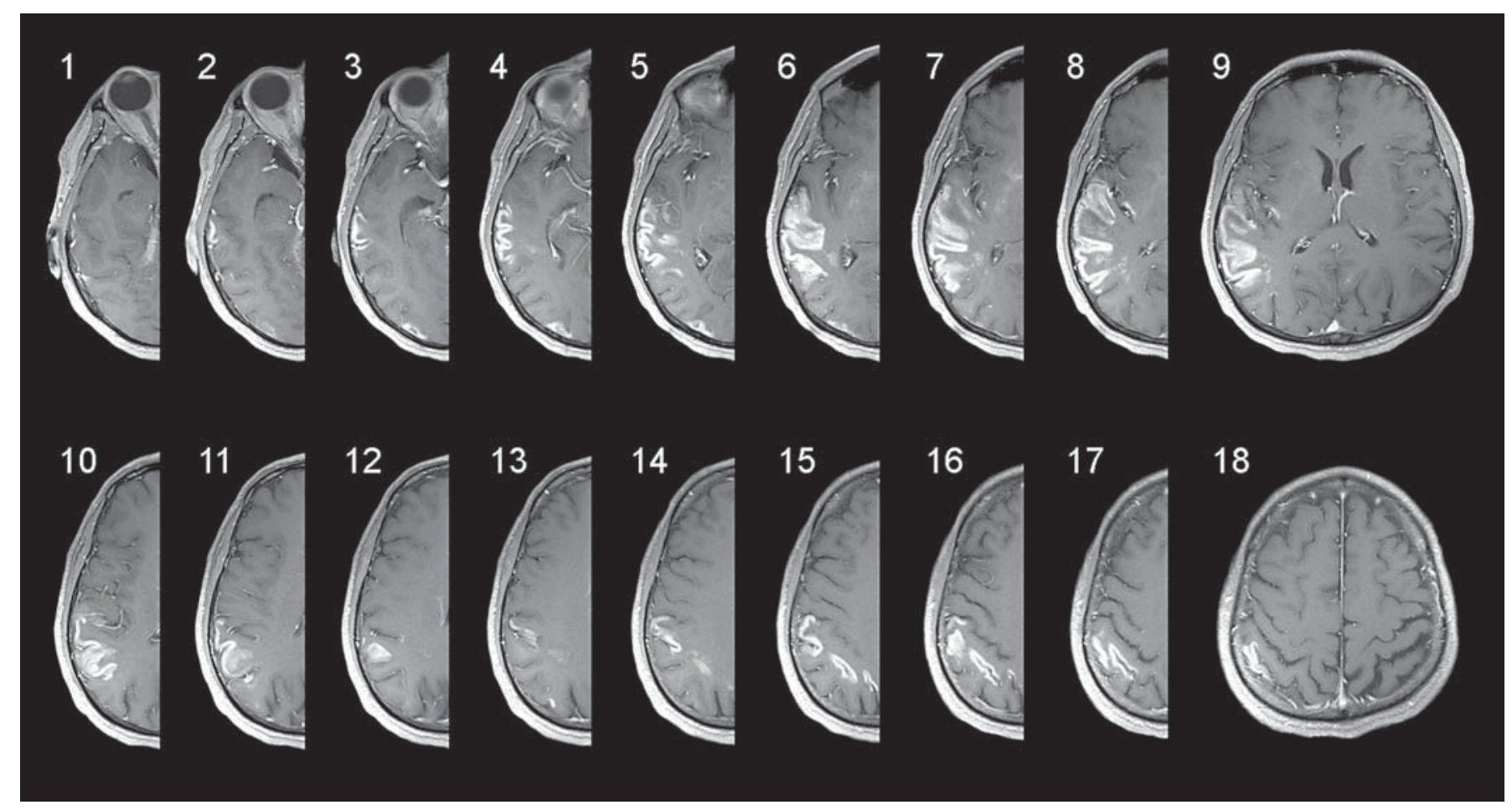

Fig. 1. MRI at day 16 after symptom onset. $T_{1}$-weighted, gadolinium-enhanced, horizontal MRI sections demonstrating the subacute stroke within the right hemisphere. The precise localization using Talairach templates revealed an involvement of the middle and superior temporal (sections 2-12), fusiform (4-6), angular (11-16) and supramarginal gyri (13-18).

finally, a partial alteration of written sentence comprehension; calculation - oral (partial loss of multiplication tables) and written (complete procedural loss in subtractions and multiplications) acalculia; constructive praxis - deficit in programming the copy of a cube without space disorder between elements, the drawing was done step by step with hesitation and slowness, and the basic structure not properly extracted; right and left perception - errors in relation to his own body and to the examiner's body; finger gnosis - signs of digital agnosia: with eyes shut, the patient was not able to discriminate the number of fingers between 2 stimulated fingers and the number of joints stimulated on the same finger, even though he correctly identified his fingers by name and could lift the touched finger; spatial attention - slight left visual hemineglect (significant right directional bias in line bisection, rare left reading omissions and slowing down during the transition to the next line) and slight left auditory hemineglect (asymmetry to the disadvantage of the left ear in the diotic listening test); memory - severe memory impairment in the visual recognition of landscapes but not of words, with 30 and 3 errors, respectively, out of 40 items tested; executive functions - deficits in planning alternating drawing (frises de Luria) characterized by a slow realization, poor performances in verbal and figural fluency tests and important difficulties in understanding instructions specific to executive tasks that involve a shift between 2 criteria, respect of rules and the extraction and maintenance of log- ical criteria for classification, and attention - slowed reaction time and attentional fluctuations.

In summary, we observed a relatively preserved awareness of cognitive disorders, slight language alterations, elements of Gerstmann's syndrome, moderate constructive apraxia, slight left auditory and visual hemineglect and severe nonverbal memory impairment.

An MRI scan, obtained at day 16 after symptom onset, revealed a right posterior MCA stroke, with no contralateral lesion. Lesion analysis was performed using the Talairach atlas of brain coordinates (www.talairach.org) by superimposing the corresponding Talairach section on each MRI section. It revealed a brain infarct involving the right middle and superior temporal, fusiform, angular and supramarginal gyri (fig. 1), which suggested an occlusion of both the angular and posterior temporal arteries, described by Foix and Lévy [17] as a temporoangular infarct.

\section{Discussion}

The clinical picture first evoked a reversed cerebral lateralization with elements of Gerstmann's syndrome consecutive to a right posterior MCA stroke: right-left confusion, acalculia of the anarithmia type, signs of digital agnosia and apraxic agraphia characterized by a disruption of skilled movement plans of writing, principally leading to distorted, hesitant and imprecise letter formation. The slight hemineglect observed could be congruent 
with this reversed cerebral lateralization, as it could be seen in left MCA strokes of classically lateralized patients. This was also true for the difficulties in the constructive praxis (programming deficits without spatial disruption), difficulties which, again, are usually described after right-hemispheric lesions in classically lateralized patients. Furthermore, there was no anosognosia for the cognitive deficits. Another element which supported this hypothesis was the awareness of the disorders, and the frustration and anxiety felt by patients after a right infarct [18].

This hypothesis of a reversed cerebral lateralization was, however, not confirmed for all cognitive functions. Indeed, the lesion localization could have induced more severe language deficits or ideomotor and/or ideational apraxia. We hypothesized that the slight language deficits observed could be due to a bilateral processing of this function.

Finally, severe nonverbal memory impairment is more congruent with a classical lateralization of cognitive functions.

We conclude that our patient presented an atypical representation of the cognitive functions, with some elements evoking a reversed lateralization and others suggesting a classical and, potentially, a bilateral lateralization. This case illustrates the heterogeneous functional organization of the brain in a left-handed patient [6]. Interestingly, this organization did not disrupt cognitive functions prior to the cerebrovascular event, as has previously been described for other cases of nonstandard lateralization as well $[2,3]$.

\section{Acknowledgments}

The authors thank Drs. David Magezi, Micah Murray and Claire Bindschaedler for their critical review of this paper and their valuable comments.

\section{References}

1 Rasmussen T, Milner B: The role of early left-brain injury in determining lateralization of cerebral speech functions. Ann NY Acad Sci 1977; 299:355-369.

2 Floel A, Buyx A, Breitenstein C, Lohmann H, Knecht S: Hemispheric lateralization of spatial attention in right- and left-hemispheric language dominance. Behav Brain Res 2005;158:269-275.

3 Floel A, Knecht S, Lohmann H, Deppe M, Sommer J, Drager B, Ringelstein EB, Henningsen $\mathrm{H}$ : Language and spatial attention can lateralize to the same hemisphere in healthy humans. Neurology 2001;57:10181024 .

4 Knecht S, Drager B, Deppe M, Bobe L, Lohmann H, Floel A, Ringelstein $\mathrm{EB}$, Henningsen $\mathrm{H}$ : Handedness and hemispheric language dominance in healthy humans. Brain 2000;123:2512-2518.

5 Basso A, Farabola M, Grassi MP, Laiacona M, Zanobio ME: Aphasia in left-handers: comparison of aphasia profiles and language recovery in non-right-handed and matched right-handed patients. Brain Lang 1990;38:233-252.

6 Jörgens S, Kleiser R, Indefrey P, Seitz RJ: Handedness and functional MRI activation patterns in sentence processing. Neuroreport 2007;18: 1339-1343.

7 Alexander MP, Fischette MR, Fischer RS: Crossed aphasias can be mirror image or anomalous: case reports, review and hypothesis. Brain 1989;112:953-973.

8 Lessa Mansur L, Radanovic M, Santos Penha S, Iracema Zanotto de Mendonca L, Cristina Adda C: Language and visuospatial impairment in a case of crossed aphasia. Laterality 2006;11:525-539.

9 Selnes OA, Pestronk A, Hart J, Gordon B: Limb apraxia without aphasia from a left-sided lesion in a right-handed patient. J Neurol Neurosurg Psychiatry 1991;54:734-737.
10 Margolin DI: Right-hemisphere dominance for praxis and left-hemisphere dominance for speech in a left-hander. Neuropsychologia 1980; 18:715-719.

11 Padovani A, Pantano P, Frontoni M, Iacoboni M, di Piero V, Lenzi GL: Reversed laterality of cerebral functions in a non-right-hander: neuropsychological and spect findings in a case of 'atypical' dominance. Neuropsychologia 1992;30:81-89.

12 Dronkers NF, Knight RT: Right-sided neglect in a left-hander: evidence for reversed hemispheric specialization of attention capacity. Neuropsychologia 1989;27:729-735.

13 Alexander MP, Annett M: Crossed aphasia and related anomalies of cerebral organization: case reports and a genetic hypothesis. Brain Lang 1996;55:213-239.

14 Oldfield RC: The assessment and analysis of handedness: the Edinburgh Inventory. Neuropsychologia 1971;9:97-113.

15 Wintermark M, Reichhart M, Cuisenaire O, Maeder P, Thiran JP, Schnyder P, Bogousslavsky J, Meuli R: Comparison of admission perfusion computed tomography and qualitative diffusion- and perfusionweighted magnetic resonance imaging in acute stroke patients. Stroke 2002;33:2025-2031.

16 Verstichel P, Meyrignac C: Left unilateral melokinetic apraxia and left dynamic apraxia following partial callosal infarction. Rev Neurol 2000;3:274-277.

17 Foix C, Lévy M: Les ramollissements sylviens. Rev Neurol 1927;1:151.

18 Nagaratnam N, Phan TA, Barnett C, Ibrahim N: Angular gyrus syndrome mimicking depressive pseudodementia. J Psychiatry Neurosci 2002;27:364-368.

Alexandre Croquelois, MD

Neuropsychology and Neurorehabilitation Service

Centre Hospitalier Universitaire Vaudois and University of Lausanne Avenue Pierre-Decker 5, CH-1011 Lausanne (Switzerland)

Tel. +41 21314 14 76, Fax +41 213147756

E-Mail alexandre.croquelois@chuv.ch 